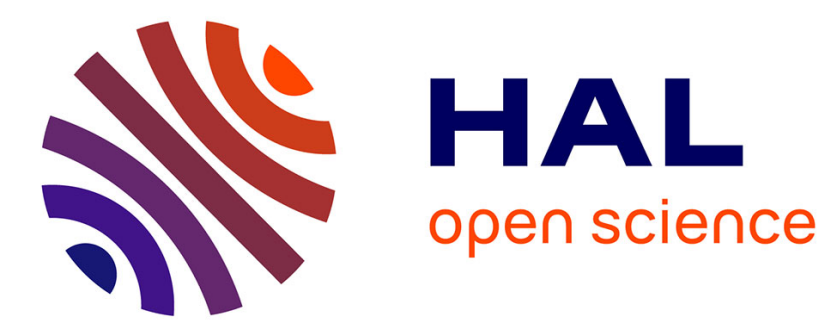

\title{
Study of water stress and droughts with indicators using daily data on the Bani river (Niger basin, Mali) \\ Philippe Roudier, Gil Mahe
}

\section{To cite this version:}

Philippe Roudier, Gil Mahe. Study of water stress and droughts with indicators using daily data on the Bani river (Niger basin, Mali). International Journal of Climatology, 2010, 30, pp.1689-1705. $10.1002 /$ joc.2013 . hal-00566014

\section{HAL Id: hal-00566014 https://hal.science/hal-00566014}

Submitted on 15 Feb 2011

HAL is a multi-disciplinary open access archive for the deposit and dissemination of scientific research documents, whether they are published or not. The documents may come from teaching and research institutions in France or abroad, or from public or private research centers.
L'archive ouverte pluridisciplinaire HAL, est destinée au dépôt et à la diffusion de documents scientifiques de niveau recherche, publiés ou non, émanant des établissements d'enseignement et de recherche français ou étrangers, des laboratoires publics ou privés. 


\title{
Study of water stress and droughts with indicators
}

\author{
using daily data on the Bani River (Niger basin,
}

\section{Mali)}

Philippe Roudier ${ }^{\mathrm{a}, 1}$ and Gil Mahe ${ }^{\mathrm{b}}$

${ }^{a}$ CIRED, Campus du jardin tropical, 45 bis ave de la Belle Gabrielle, 94736 Nogent sur Marne Cedex, France

${ }^{\mathrm{b}}$ IRD, HydroSciences Montpellier, Université Montpellier 2, Case MSE. Place Eugène Bataillon, 34095 Montpellier, France

\begin{abstract}
As in most part of Africa, the Bani basin (Niger River, Mali) is threatened by climate changes. This study focuses on droughts hazard and its indicators as derived from the Climatic Moisture Index using the monthly data for the period (1963-2000), in order to examine the Bani basin vulnerability to water stress. In this study, water deficit (drought) was logically addressed using the Standardized Precipitation Index at a 10 days time step. The inadequacies in the Standardized Precipitation Index while estimating water deficit within the basin based on technical issues result in the usage of the Effective Drought Index (EDI). This robust index is

\footnotetext{
Corresponding author

E-mail: roudier@centre-cired.fr

Tel : +33 143947367
} 
specially designed for daily data computation and uses daily data efficiently while estimating water deficit. Three regions were identified to be threatened by droughts (length, number and evolution in time) within the basin, using EDI as a tool of investigation. It also shows that droughts seem to be less frequent but of a longer duration due to the increasing trend of total dry days over the study period.

Key words: index, CMI, SPI, EDI, Mali, drought, vulnerability, Bani, Niger basin

\section{Introduction}

Recent studies have shown that climate change will have a strong impact on Africa, most especially in the agro-pastoralist regions (IPCC, 2007) like Bani basin which is located within the upper Niger River basin. In an attempt to address the basin vulnerability to climate change, the RESSAC program (surface water resources vulnerability to mid-term climatic and anthropogenic evolutions in Sahelian regions) was initiated by the French Institute for Development (IRD) and funded by the French National Agency for Research (ANR).

Vulnerability is a very wide concept, with several definitions (Füssel and Klein, 2006), that demand several dataset, if satisfactory assessment of a region vulnerability to climate change is to be attained. This is evident in Water Poverty Index computation (and its evolution: Climate Vulnerability Index) by Sullivan and Meigh (2005).

This study therefore entails assessment of droughts hazard which constitute only a fraction to the understanding of vulnerability concept, although all aspects of vulnerability to drought are not assessed due to inadequate information on the 
adaptation capacity (water supply system, access to irrigation...) within the region. O'Brien et al. (2007) and Downing and Patwardhan's (2006) provide more useful information on vulnerability to climate change.

In the study no attempt was made to re-defined drought but the concept remains within the several drought definitions (Traore et al., 2000). Also, water stress and drought assessment within Bani basin was carried out using vital droughts occurrence indicators, since with standardized indicators, estimation of drought indicators can easily be computed over space and time (Eriksen and Kelly, 2006). Such indicators remain useful tools for stakeholders (Feitelson and Chenoweth, 2002) and future vulnerability estimation.

This study therefore aims at providing useful drought indicators to researchers working on climate change and agricultural related issues. Eriksen and Kelly (2006) provide details on the usefulness of these indicators.

In addition, in an attempt to study the distribution and evolution of droughts within the Bani basin, an overview of drought analysis was carried-out using the Climatic Moisture Index which was computed from the monthly data. The Standardized Precipitation Index (SPI) was also computed at a 10 days time step using daily rainfall data for more detailed information on the drought occurrence and magnitudes. The inadequacies of the SPI and the need for detailed information on drought intensity and length, and classification of threatened regions, led to the estimation of the basin Effective Drought Index. 


\section{Study area and data}

The Bani basin is located within the upper part of Niger River (Figure 1); larger portion of the basin is located within Mali and extends to Burkina Faso and Ivory Coast. The surface of the basin is about $120000 \mathrm{~km}^{2}$ (when considering an outlet located at Beneny Kegny in Mali).

Two data sets were available for usage within the basin. The first is derived from the CRU (Climatic Research Unit of East Anglia University, UK) monthly data at a 0.5 square degree resolution, which are entered into a hydrological model (Paturel et al., 2003a; Dezetter et al., 2008) at the basin scale, to calculate monthly rainfall and PET times series for the basin for the years 1940-1995 and 1940-1999 respectively.

The second dataset is a mix of two different daily rainfall databases, although such practice ought to be avoided, the need to reach an acceptable spatial resolution justifies our choice. The first database comes from the French Institute for Development (IRD) in Bamako (Mali) and the second one from the HSM Laboratory in Montpellier (France), namely from the SIEREM database (Boyer et al., 2006; Rouche et al., 2008).

51 stations were selected (Figure 2) based on two criteria: time series must extend over the 1963-2000 period and have less than 10\% (Romero et al., 1998) record gaps. The only deviation from this rule are 3 stations namely Filamana, Zangasso, Konseguela, with less than $15 \%$ of record gaps (Figure 3).

The spatial resolution adopted for the classification of the regions provides an optimal result within the basin, except for a region without any information represented with dashes on maps. 
Two different methods were used to fill in the missing data in the daily rainfall time series. The first method uses a classical multi correlation using the closest stations within a homogeneous region. The homogeneous regions were defined based on Soumaguel's recommandations (Soumaguel, 1996) following the general shape of isohyets (Figure 2). But $\mathrm{R}^{2}$ coefficients are frequently very low, which means that this method is frequently inaccurate. The second method uses a two-step approach: first, the same multi correlation method as previously is performed but only when the $\mathrm{R}^{2}$ coefficient is higher than 0.60. If not, we used a simple statistical approach. Daily rainfall values were, for each station and for each month, classified in categories (e.g [2; $4 \mathrm{~mm}]$ ) with a given probability of occurrence. Then, a uniform distribution of values between 0 and 1 is simulated. One value is attributed to each daily gap and is considered as the probability of occurrence of the category formerly created. For example, let's assume a gap in record whose corresponding value from the uniform distribution is 0.4. Then we look for the interval of rainfall with the same probability of occurrence, e.g [2; $4 \mathrm{~mm}]$. Finally, the missing rainfall value is $3 \mathrm{~mm}$, the central value.

To assess which method is the best, monthly values were compared with daily values added up on a month. The first method always underestimates monthly values, although the second one performs well. Thus, the study will be led with data filled thanks to method $n^{\circ} 2$. 


\section{An overview of water stress using the Climatic Moisture Index}

\subsection{Definition}

This index is expressed as the ratio of annual precipitation to potential evapotranspiration (PET), with ranges between -1 and 1. The index evaluates water scarcity with the usage of few data (Vörösmarty et al., 2005) and is defined as follows:

$$
\begin{aligned}
& \mathrm{CMI}=(\mathrm{P} / \mathrm{PET})-1 \text { if } \mathrm{P}<\mathrm{PET} \\
& \mathrm{CMI}=1-(\mathrm{PET} / \mathrm{P}) \text { otherwise }
\end{aligned}
$$

According to Vörösmarty (2005), there is a classification link between CMI values and climatic conditions $(\mathrm{CMI}<-0.6$ : Arid. $-0.6<\mathrm{CMI}<0$ : Semi-arid. $\mathrm{CMI}>0$ : Humid)

\subsection{Results}

Maps depicting rainfall pattern and trend for the periods 1940/1970 and $1971 / 1995$ are drawn, as several works have given 1970 as the beginning of the rainfall deficit in West Africa in average (Mahe et al., 2001; L'hote et al, 2002; Paturel et al, 2003b), as shown in the rainfall dataset plot Figure 4, with the rupture in 1970 according to the different detection tests available in the Khronostat software (LubesNiel et al., 1998). The rainfall and runoff changes in 1970 are very well marked over the Bani River (Mahe et al., 2000), and at a larger scale for other rivers of West Africa 
(Mahe and Olivry, 1999) using the same software. It is also remarkable that for the Bani River the lowest value of CMI is recorded in 1993, and not in 1983, which has recorded the lowest rainfall and runoff in West Africa over the $20^{\text {th }}$ century (Mahe and Olivry, 1999).

CMI values are represented on the Figure 5 for the periods 1940/1970 and 1971/1995 together with their Variability Coefficients (CV) within the Bani basin, i.e the ratio of the standard deviation to the average (of CMI values for a given period): $\mathrm{CV}=\sigma /$ mean .

\subsection{Discussion of CMI results}

The general CMI pattern is similar to that of the annual rainfall (Figure 2), with a deformation along the central eastern area. It also worth noted that the CMI decreases in the whole basin during the period 1971/1995 in regard of the average during the years 1940/1970. The arid zone which is located on the extreme northern part has extended greatly during the 1971/1995 period. A fraction of the humid region in the South is now semi-arid while the wet region has disappeared.

The Coefficient of Variability are higher during the period 1940/1970 than during the period 1971/1995: this might have resulted from higher CMI values for the $1940 / 1970$ period than for the 1971/1995 one, as noted before. Coefficient values greater than 1 might have resulted from error in data processing, since such values are not recorded by Vörösmarty (2005). Moreover, CV values are here negative almost everywhere because CMI mean is negative. 
According to $\mathrm{CMI}$ and $\mathrm{CV}$ values we can conclude that climate is getting drier since 1970 but, surprisingly, also more stable on the whole basin. The southern part of the basin is also always wetter than the northern one but more variable. Hence, during some years, CMI values in the South can be very low showing the possibility of droughts. Agricultural vulnerability of the southern part of the basin may therefore be high. A final assessment on this point is not possible considering CMI's coarse temporal resolution and lack of data after 1995.

\section{Drought study using the SPI and the SPI}

A review of drought analysis indices is given in Ntale and Gan (2003); Smakhtin and Hugues (2007), among which is described the Standardized Precipitation Index (McKee et al., 1993) which was used in this study. This choice is due to the availability of precipitation data and the non availability of temperature and PET data for the selected stations within the region on a daily time scale. This indicator has also been frequently used in different parts of the world (Giddings et al., 2005 ; Wu et al., 2001, Sönmez et al., 2005) with better spatial representation than any other common indicator, for example the Palmer Drought Severity Index (Lloyd-Hughes and Saunders, 2002). It is also very practical because of its normalization since drought occurrence thus is associated to a return period.

However, as noted by Lloyd-Hughes and Saunders (2002), usage of SPI at short time scales $(1,2$, or 3 months) within regions being characterized by low seasonal precipitation might result in the over-estimation or under-estimation of the positive or negative SPI values as seen in this study. 
In this study, SPI was carried-out at a 10 days short time step within a region being characterised by high seasonal precipitation (approximately from June to September). In order to avoid the seasonality problem being associated with SPI quoted before, the analyses were carried-out during the months of July to September which constitute the core of the rainy and agricultural growing seasons.

The choice of a 10 days time step is due to the need to provide useful information about drought that can adequately support future agronomical use.

\subsection{SPI Definition}

\subsubsection{General}

SPI is based on fitting a density function (and its cumulative probability distribution) with the averaged precipitation data, which is usually carried out using Gamma distribution (Guttman, 1999); average can be calculated at different timescales. The computed distribution is later transformed into normal distribution as illustrated in Figure 6. The SPI is finally computed with 0 being the centre value. The classification scheme given in Table 1 (Lloyd-Hughes and Saunders, 2002) is a reflection of the computed values. 


\subsubsection{SPI estimation}

The SPI estimation involves two different steps; the first one is the calculation of a 10-day average precipitation on a daily moving window. These decadal values are then used to calculate the associated density function. In the second step we search for the fitness of this density function to a Gamma distribution. The fitness was carried-out using Anderson-Darling fit test, which seems to be more robust than the $\mathrm{Chi}^{2}$ and Kolmogorov-Smirnov tests (Meylan and Musy, 1996; Hamed and Rao, 2000). R software package nsRFA was used for the quality of the fit tests (R Development Core Team, 2005).

The test was carried-out for 51 selected stations using gamma distribution. At $90 \%$ and $95 \%$ confidence levels, 50 and 49 selected stations were rejected, respectively.

Hence, for a better representation of the dataset, a systematic selection was carried-out of the 10 days average values, one day every 5 days, i.e days $5,10,15,20$, 25, 30 for each month, instead of 10 days values everyday (i.e days $1,2,3 \ldots, 30$ ). With this new approach, only 3 stations are rejected at 95\% confidence level. Although, this approach provides a better data representation, the results is not as precise as working with the mean daily dataset. For example, different drought duration could be computed using the two methods. There is therefore a need to estimate the efficiency of this method. 


\subsubsection{Assessment of precision after degradation}

Assessment of the efficiency of the systematic selection of one day every 5 days is accompanied by a comparative analysis of computed parameters such as drought duration, between the 'normal' and the 'degraded' methods for selected stations with Kouto station, the only station accepted using the first approach (mean 10 days value computed everyday). It should be noted that this study focuses on mean drought duration, maximum drought duration, number of droughts and precipitation threshold (i.e rainfall value for a decade to be considered in "drought").

Drought duration is the number of consecutive days with negative SPI value: the number of droughts is different from the number of dry days. For example, three consecutive days having a negative SPI value, only translate to 1 drought event. Comparison between 'degraded' and 'original' SPI-10d values using R software package lmomco (functions pargam and $c d f g a m$ ) and package stats (function qnorm) (R Development Core Team, 2005) is presented in Table 2.

From the results, it can be said that the method fails to adequately represent the drought incidence since the mean drought duration of the 'original' SPI is to a large extent smaller than the modified one, and the mean drought occurrence is larger than the original SPI. There is a need therefore to increase the sampling size through selection of more stations, apart from Kouto (at least one for each of the 5 homogeneous regions), if a "correction parameter" that adequately supports classical SPI is to be attained.

Meanwhile, the comparative analysis of the maximum drought duration and precipitation threshold between original and degraded version provides a good correlation. 


\subsubsection{Results}

The maximum drought duration and precipitation thresholds indices, the two parameters which remains the focus of this study as generated from the 'degraded' SPI10d are shown in Figure 7 and Figure 8, respectively.

\subsubsection{Maximum Drought Duration (MDD)}

The maximum drought duration is shown in Figure $7 \mathrm{a}$ and Figure $7 \mathrm{~b}$ for droughts magnitudes of SPI-10d $<0$ and extreme+severe droughts (SPI-10d<-1.5).

Regions with highest SPI $<0$ droughts duration are not the same than those for severe+extreme droughts $(\mathrm{SPI}<-1.5)$ and for $\mathrm{SPI}<0$ droughts. Figure 7 a depicts high SPI $<0$ droughts duration within the basin eastern border and none at the northern region, although Figure $7 \mathrm{~b}$ shows higher values in the North.

This shows that examination of the different drought occurrences apart from the $\mathrm{SPI}<0$ droughts is necessary.

\subsubsection{Precipitation threshold}

Precipitation threshold parameter is highly useful due to its practical application while studying drought event and while addressing issues relating to irrigation water management. Thanks to this tool, it is very easy to know (for stakeholders, water managers...) when a drought situation occurs through the 10 days average. The 
thresholds value for droughts and extreme droughts are shown in Figure 8 (a and b, respectively).

The structure of the precipitation threshold map is similar to annual isohyets, especially for the extreme drought values (Figure 8b), where the basin area is clearly divided following a Northwest to Southeast line. Meanwhile, a deformation, similar to the CMI formation was noticed towards the Eastern portion of the basin.

\subsection{Effective Drought Index}

\subsubsection{Description}

As it has been showed, the SPI does not provide all the information needed on drought occurrence within Bani basin. This calls for the use of a relatively new index, namely the Effective Drought Index. This index has been especially developed by Byun and Wilhite (1999), for daily rainfall data computation and analysis.

It should be noted that EDI is not frequently used for drought analysis and is more difficult to understand as well as more difficult to calculate while compared to SPI. It has been proved to be more robust than the SPI (Morid et al., 2006), while analyzing drought occurrence.

The EDI is based on the concept of Effective Precipitation (EP) which represents the "daily water resources depletion". The index is (Byun and Wilhite, 1999) quantitatively expressed as:

$$
E P i=\sum_{n=1}^{i}\left[\left(\sum_{m=1}^{n} P m\right) / n\right]
$$


With $i$ Duration of Summation (DS), $P_{m}$ precipitation of $m$ days before and $E P i$ the Effective Precipitation for a day considering i days before.

The summation duration can have different values like 365 days, 15 days.... In this study, the same approach as with the SPI-10d was adopted, i.e the Effective Precipitation calculation is based on the 10 days before the $\mathrm{D}$ day. The 10 -days window is the dummy DS value which is used to compute the final EDI.

Byun and Wilhite (1999) paper provides useful information on EDI which is expressed as:

$$
\begin{gathered}
\mathrm{EDI}_{\mathrm{j}}=\mathrm{PRN}_{\mathrm{j}} / \mathrm{ST}\left(\mathrm{PRN}_{\mathrm{j}}\right) \\
P R N j=\frac{D E P j}{\sum_{\mathrm{n}=1}^{j} 1 / \mathrm{n}} \\
\mathrm{DEP}=\mathrm{EP}-\mathrm{MEP}
\end{gathered}
$$

where $M E P$ is the mean $\mathrm{EP}, j$ is the number of days over which precipitation deficit is accumulated, $S T$ is the standard deviation, and $P R N$ is Precipitation needed for a Return to Normal, i.e for "the recovery from the accumulated deficit since the beginning of a drought" (Morid et al., 2006)

It should be noted that EDI has similar classification, very close to SPI code (Morid et al, 2006) with modification for the creation of "mild drought" class as shown in Table 3. 
After this calculation step, which involves the use of $\mathrm{R}$ script, the following parameters, namely mean drought duration; maximum drought duration and number of droughts, were estimated. A drought duration is defined as the number of consecutive days with $\mathrm{EDI}<0$ (or $\mathrm{EDI}<-1.5$ for extreme and severe droughts). With these 3 parameters, it is interesting to study the spatial drought distribution for the period 1963/2000 and drought temporal evolution between 1963/1970 and 1971/2000.

Even though, it should have been more precise to use the same length of years before and after 1970, this was not possible considering the very limited number of stations with such a long dataset.

\subsubsection{Results from the EDI}

\subsubsection{Drought duration}

Figures 9 and 10 depicts the varied droughts $(\mathrm{EDI}<0$, ) and extreme+severe droughts $(E D I<-1.5)$ with their spatial distribution of maximum drought duration, mean drought duration and its variation, respectively.

\subsubsection{Number of droughts}

Figures 11 and 12 show the varied drought frequency for all kind of droughts $(\mathrm{EDI}<0$,$) and extreme+severe droughts (\mathrm{EDI}<-1.5)$, i.e of groups constituted of consecutive days with negative EDI value. 


\section{Discussion}

\subsection{Analysis of EDI distribution}

\subsubsection{Spatial drought distribution}

Droughts are more frequent but of shorter duration in the southern area of the basin: this trend is especially strong for the MDD but also for the average duration (about 1 day longer).

The mean duration of droughts is longer in the North for both classes of EDI values, but the highest values of mean or maximum values of drought duration are not observed in the extreme North, but slightly southward, along an area crossing the basin from the Central Northwest to the Central Northeast. Locally high values of EDI are also observed in the South of the basin, but without overall geographical organisation. It is to be noted that for two stations in the Central Southwest of the basin, the mean duration of drought has decreased $(\mathrm{EDI}<0)$ over the period 1963-2000, during July to September months (Figure 9b). This is confirmed with extreme+severe droughts (EDI<1.5), but with more stations concerned in the South, and even some in the Central North band.

As shown in Figures 9 to 12, MDD is about 40 days longer in the Northern portion of the basin, as apparent in the North western quarter of the basin, while the extreme Northern portion has drought duration that is similar to the Southern mid-area.

Comparative analysis of the varied droughts being studied (EDI $<0$ and EDI $<-$ 1.5), shows no significant spatial differentiation in their frequencies as shown in Figure 
11a and 12a. However, concerning drought duration, Figure 9b shows much higher MDD in the North than in the South while Figure $10 \mathrm{~b}$ presents a more homogeneous situation for extreme+severe droughts only.

It should be noted that regions with less frequent drought are noted to be experiencing longer drought days; this provides a pretty bad situation for agricultural activities.

However, for a small region located at the Central West (Bougouni, Dogo Bougouni...) both parameters depict a decreasing trend.

\subsubsection{Temporal variability}

Comparative analysis of the various droughts studied $(\mathrm{EDI}<0$ and $\mathrm{EDI}<-1.5)$, shows varied temporal variation while areas with less frequent drought usually experience longer drought duration, this pattern is much evident for $\mathrm{EDI}<0$ droughts (Figures $11 \mathrm{~b}$ and 12b). Also, extreme+severe droughts frequency seems to increase with an increasing trend after 1970, in regions located within the northern part of the basin.

Figure 13 shows the categorization of drought days frequency for the 'drought conditions' and 'extreme+severe conditions' (i.e number of days with negative (and < 1.5, respectively) EDI value) within Bani catchment.

The number of drought days is higher during the 80 s which is the driest decade since the beginning of the century over the area (L'Hote et al., 2003). High values are also observed during the 90s, but with also more frequent low values of EDI for extreme+severe droughts during this decade (Figure 13b). 
5.2 Summary map of Drought analysis

One of the problem associated with drought indicator is the large number of information to be provided, hence it is difficult to have a global view of droughts in a general way. Hence, in this study the stations are categorized from the less to the most threatened by droughts using EDI. This classification provides an instant virtual assessment of drought occurrence within Bani basin. It is also very important to study other associated maps like MDD and number of droughts, among others, since each map is a part of the final general assessment.

The drought classification map is based on 4 main criterions namely number of droughts, mean drought duration, maximum drought duration and temporal evolution. "Temporal evolution" is the sum of the 3 previous criterions' relative evolution between years 1963/1970 and years 1971/2000.

Temp. Evol. $=\left(\frac{\text { Nbr of droughts }(71 / 00)}{\text { Nbr of droughts }(63 / 70)}-1\right)+\left(\frac{\text { Max D. Duration }_{(71 / 00)}}{\text { Max D. Duration }(63 / 70)}-1\right)+\left(\frac{\text { Mean D. Duration }_{(71 / 00)}}{\text { Mean D. Duration }(63 / 70)}-1\right)$

For each 4 criterion described above, the 51 stations are ranked from the worst to the best situation and the final rank is the average of these 4 parameters.

Moreover, in order to provide a more quantitative assessment to extreme and severe droughts, weights were attached to each criterion. For example, the maximum drought duration estimation ranking involves consideration of various drought $(\mathrm{EDI}<0)$ for each station, while a second rank considers only droughts with EDI $<-1.5$. These two ranks are then averaged and the average value remains the rank for 'maximum drought duration' for the station. This is summarized below:

$$
F R=\frac{R(\text { Number of droughts })}{+R_{(\text {Mean Drought Duration })}+R_{(\text {Max Drought Duration })}+R_{(\text {Temporal Evolution })}}
$$


With, for example:

$$
R_{(\text {Max Drought Duration })}=\frac{R_{(\text {Max Drought Duration }(\mathrm{EDI}<0))}+R_{(\text {Max Drought Duration }(\mathrm{EDI}<-1.5))}}{2}
$$

With:

FR: Final Rank, calculated for each station.

RX: Rank for category " $\mathrm{X}$ ". $\mathrm{R}=\{1,2, \ldots, 51\}, 1$ being the worst situation i.e highest number of droughts, longest duration and strongest positive evolution of these parameters.

It is important to note that these 2 parameters that address drought duration have been used in order to provide a better weighted assessment for each station. Finally, Figure 14 shows the station ranking within the Bani basin, which depicts that three regions seem to be threatened by droughts: the southern quarter (Filamana, Manankoro, Odienne...), the Northeast (Dionkele, Zangasso, Klela...) and the Central West (Fana, Dioila, Beleko...). The extreme northern part is surprisingly not in a bad situation, like the centre of the basin. The whole Central South of the basin (Bougouni, Kolondieba, Sikasso) seems to be the less affected by the drought hazard during the 1963-2000 period.

Such a geographical structure might be due to a coincidence. It may also reflect some long term climatic organisation. To what this could be related has to be searched for instance into atmospheric and climatologic features. This is not the topic of this paper. But we can nevertheless put forward a hypothesis, which is that this structure could be linked to the average location of the rainiest area of the Intertropical Convergence Zone during the rainy season. On this subject Lienou et al. (2008) have recently shown in Central South Cameroon a southward shift of the climatic areas 
during boreal summer since 1970 , which they tentatively connected to the rainfall reduction over West Africa since 1970.

\subsection{SPI vs EDI}

The SPI-10d calculation provides less accurate results than expected for some values but is quite accurate for Maximum Drought Duration. Hence, it is interesting to compare MDD results from the SPI and EDI maps which are very similar. It should be noted that the temporal resolution of the degraded SPI-10d is 5 days (the 10 days wide temporal window is moving every 5 days)

Due to the differences in temporal resolution (1 day for the EDI vs 5 days for the SPI), further comparison between these indicators is quite difficult. Nevertheless, it is possible to try a comparison with a degraded EDI resolution. This was carried-out using calculated mean value every 5 days, in order to assess the similarity of each 5 days period and their categorization, with the SPI and the EDI.

The result of the classification is given in Table 4: if both categories (one assessed by the SPI, the other by the EDI) are the same then the classification is "good", if there is just one category between both, classification is "intermediate", and if there is more than one category, classification is "bad".

Results show that both indicators give results which are quite close but the difference is nevertheless noticeable. This confirms our previous view concerning SPI degradation which is not a bad estimator but it is not good enough.

The comparison of the SPI and EDI global map (Figure 15, a and b) provides similar final assessment because the classification is based on ranks and not on values. 
But, if similarities do exist between SPI and EDI global assessment, it differs for some regions. Figure $15 \mathrm{~b}$ depicts the final drought assessment but with a less complicated droughts definition as days without any rainfall.

Moreover, the role played by these indicators is well depicted by these three maps (Figures 15a, 15b and 15c). Without giving an elaborated definition of droughts (Figure 15b), would have led to skip the critical situation in the southern part of the basin.

Finally, SPI-10d is still interesting for some parameters, even if EDI seems better to us, since it also gives valuable information for MDD and precipitation thresholds. Summary of both indicators advantages are given in Table 5.

\subsection{Link with CMI}

EDI estimation is globally coherent with CMI. It is also evident that water stress has increased within the entire basin after year 1970. This idea is confirmed by the temporal evolution of droughts as noted in section 3.3. There is a trend in the South eastern part of the basin where CMI values are more decreasing than in the rest of the basin. Final EDI assessment map provides similar information that there exists a threatened region near the South eastern border. 


\section{Conclusion}

\subsection{Summary}

This work aimed at studying droughts occurring in the Bani basin (Mali) using indexes at different time steps. Indexes were computed because they are useful to compare different situations over time and space but also because they give a standardized definition of droughts.

The computed CMI using monthly PET and rainfall data provides the first indication of the water stress with an increasing trend all over the basin after 1970, the critical year in this region. Indeed, the part of the basin classified as humid for years 1940-1970 disappeared for years 1971-1995 and the arid zone got much larger.

Further drought analysis was provided using the Standardized Precipitation Index at a 10 days time step. Although totally unsuccessful computed with the 'classical' definition it provides however quite good information with a 'degraded' definition: maximum drought duration and precipitation threshold for each drought category. Unfortunately, important information such as mean drought duration is very imprecise.

The inadequacies of the SPI call for the usage of another index, namely the Effective Drought Index, which is more complicated but more robust with daily data analysis and computation. Moreover, the EDI does not use a statistical distribution like the gamma one for the SPI. Thus, the EDI does not reject any station which increases its accuracy. This index gives also very interesting data for agriculture purposes like mean 
and maximum drought duration. In order to have a quick overview of regions threatened by increasing drought indiceswe produced a drought assessment rank map of the basin,

Three main threatened regions identified are: the whole southern part of the basin (i.e south of the $1200 \mathrm{~mm}$ annual isohyet), the North eastern part of Bani Basin (Dionkele, Zangasso, Klela...) and the Central western part (Fana, Dioila, Beleko...).

Thanks to this drought assessment rank, it is now possible to focus first on most threatened regions for creating coping strategies such as irrigation, weather insurances or seasonal forecasts.

Moreover, it is noticed that drought situation is getting worse after 1970 and that there is an increase in the number of days being classified in drought. Indeed, if the number of events is decreasing, their duration is increasing. This tendency is especially obvious considering all types of droughts $(\mathrm{EDI}<0)$. This supports the findings made with the CMI.

Finally, the EDI provides a better tool for studying droughts than SPI-10d. The EDI also allows a more accurate description of the spatial extension of the drought than other indices like for instance the variable "days without any rainfall", which seems too simple and which use would have led to skip the extension of the drought in the South especially. Indeed, this simple approach is not "site located", which means that a drought is defined relatively to the rest of the basin. From this point of view, a 5 days drought has the same impact in the South and in the North. This is obviously wrong, as crops are very different, especially considering their drought tolerance (e.g maize vs. millet)

Using such an index seems to be very useful for agricultural purposes. For example, insurances systems based on weather information are now getting to be used 
more frequently in African countries (e.g in Malawi) and, according to Berg et al. (2008) there is a real need for robust daily or decadal index to be used.

\subsection{Limitations}

It is important to be aware of the study limitations which mainly are due to lack of data since there is no precise way to fill lacks of data at a daily time step. Hence, the results, especially values, must be taken with caution.

Another limitation is the rainy period chosen which spreads over the month of July, August and September. If it is obvious that these 3 months are in the rainy period, the rainy season can last longer than 3 months in some regions, especially in the South. Hence, the result is more for the months of July, August and September rather than for "the rainy season".

\subsection{Prospective}

It is interesting to study more precisely the relatively usefulness of the new indicator (EDI), as it has been done with the SPI. As noted, one of the main limitations of the EDI was the time needed to compute it and also its definition, with a lot of parameters. It is therefore necessary to write a script with free access for better computation of the index in a more efficient way (a package able to compute several drought indicators at a monthly time step already exists: SPATSIM, but it is not free (Smakhtin and Hughes, 2006)). This kind of indicator really has to be simple and userfriendly. 
Concerning the rainy period, it could be useful to use a variant of the EDI, the Available Water Resource Index (Han and Byun, 2006) in order to compute for each station the beginning and the end of the rainy period. This could also show if this period is changing over time. It has been found that there was no change (Traore et al., 2000) in this region, but this does not support local farmers' point of view (Roncoli et al., 2001)

Finally a summary of all methods to fill daily data gap is really necessary and the development of a precise method is indeed very important.

Acknowledgments: the author would like to thank the financial support of this project, the French National Agency for Research (ANR) through the RESSAC program, and all reviewers of this paper's English version, especially Olusegun Adeaga, from Lagos University, Nigeria.

\section{References}

Berg A, Quirion P, Sultan B. 2008. Can weather index drought insurance benefit to Least Developed Countries' farmers? A case study on Burkina-Faso. Congrès de l'Association française de science économique, Paris, septembre 2008.

Boyer JF, Dieulin C, Rouche N, Cres A, Servat E, Paturel JE, Mahe G. 2006. SIEREM: an environmental information system for water resources. IAHS Publ. 308, 19-25. 
Byun HR, Wilhite DA. 1999. Objective Quantification of Drought Severity and Duration. Journal of Climate 12: 2747-2756.

Dezetter A, Girard S, Paturel JE, Mahe G, Ardoin-Bardin S, Servat E. 2008. Simulation of runoff in West Africa: Is there a single data-model combination that produces the best simulation results? Journal of Hydrology, 354 (1-4), 203-212.

Downing TE, Patwardhan A. 2005. Assessing vulnerability for climate adaptation. In Adaptation Policy Frameworks for Climate Change: Developing Strategies, Policies and Measures, Lim B, SpangerSiegfried E, Burton I, Malone E, Huq, S. Cambridge University Press, Cambridge.

Eriksen SH, Kelly PM. 2006. Developing credible vulnerability indicators for climate adaptation policy assessment. Mitigation and Adaptation Strategies for Global Change 12: 495-524. DOI: 10.1007/s11027006-3460-6

Feitelson E, Chenoweth J. 2002. Water poverty: towards a meaningful indicator. Water Policy 4: 263281.

Füssel HM, Klein RJT. 2006. Climate change vulnerability assessments: an evolution of conceptual thinking. Climate change 75: 301-329. DOI: 10.1007/s10584-006-0329-3

Giddings L, Soto M, Rutherford BM, Maarouf A. 2005. Standardized Precipitation Index Zones for Mexico . Atmosfera Vol. 18: 33-56. ISSN: 0187-6236

Guttman NB. 1999. Accepting the Standardized Precipitation Index: a calculation algorithm. Journal of the American Water Resources Association 35(2): 311-322.

Hamed K, Rao R. 2000. Flood frequency analysis. CRC press: Boca Raton, ISBN 0-8493-0083-5 
Han SU, Byun HR. 2006. The existence and the climatological characteristics of the spring rainy period in Korea. International Journal of Climatology 26: 637-654. DOI: 10.1002/joc.1274

IPCC - International Panel on Climate Change. 2007. Climate change 2007: synthesis report. Summary for policymakers. An Assessment of the Intergovernmental Panel on Climate Change.

L'Hote Y, Mahe G, Some B, Triboulet JP. 2002. Analysis of a Sahelian rainfall index from 1896 to 2000 : the drought continues. Hydrological Sciences Journal 47(4): 563-572.

L'Hote Y, Mahe G, Some B. 2003. The 1990s rainfall in the Sahel: the third driest decade since the beginning of the century. Reply to discussion. Hydrological Sciences Journal, 48(3): 493-496.

Lienou G, Mahe G, Paturel JE, Servat E, Sighomnou D, Ekodeck GE, Dezetter A, Dieulin C. 2008. Changes of hydrological regimes in the equatorial area of Cameroon: an impact of climate change in equatorial Africa? Hydrological Sciences Journal, 53(4): 789-801.

Lloyd-Hughes B, Saunders MA. 2002. A drought climatology for Europe. International Journal of Climatology 22: 1571-1592. DOI: 10.1002/joc.846

Lubes-Niel H, Masson JM, Paturel JE, Servat E. 1998. Variabilite climatique et statistiques. Etude par simulation de la puissance et de la robustesse de quelques tests utilises pour verifier l'homogeneite de chroniques. Revue des Sciences de l'Eau 11(3), 383-408.

Mahe G., Olivry J.C. 1999. Assessment of freshwater yields to the ocean along the intertropical Atlantic coast of Africa. Comptes Rendus de l'Academie des Sciences, Series IIa, 328: 621-626. 
Mahe G, Olivry J., Dessouassi R, Orange D, Bamba F, Servat E. 2000. Relations eaux de surface - eaux souterraines d'une riviere tropicale au Mali. Comptes rendus de l'Academie des Sciences, Serie IIa, 330: 689-692.

Mahe G, L'Hote Y, Olivry JC, Wotling G. 2001. Trends and discontinuities in regional rainfall of west and central Africa - 1951-1989. Hydrological Sciences Journal, 46(2): 211-226.

McKee TB, Doesken NJ, Kleist J. 1993. The relationship of drought frequency and duration to time scale. Report of the eighth Conference on Applied Climatology: Anaheim (California).

Meylan P, Musy A. 1996. Hydrologie frequentielle, version provisoire. Departement de Genie rural, Institut d'Amenagement des terres et des Eaux: Lausanne.

Ntale HK, Gan TY. 2003. Drought indices and their application to east Africa. International Journal of climatology 23: 1335-1357. DOI: 10.1002/joc.931

Morid S, Smakhtin VU, Moghaddasi M. 2006. Comparison of seven meteorological indices for drought monitoring in Iran. International Journal of Climatology 26: 971-985. DOI: 10.1002/joc.1264

O'Brien K, Eriksen S, Nygaard LP, Schjolden A. 2007. Why different interpretations of vulnerability matter in climate change discourses. Climate Policy 7: 73-88.

Paturel JE, Ouedraogo M, Mahe G, Servat E, Dezetter A, Ardoin S. 2003a. Influence of the spatialization of data on the modelling of monthly river regimes in West Africa. Hydrological Sciences Journal. 48(6): 881-890.

Paturel JE, Ouedraogo M, Servat E, Mahe G, Dezetter A, Boyer JF. 2003b. The concept of rainfall and stream flow normals in West and Central Africa in a context of climatic variability. Hydrological Sciences Journal 48(1): 125-137. 
R Development Core Team. 2005. R: A language and environment for statistical computing, reference index version 2.6.2. $R$ Foundation for Statistical Computing, Vienna, Austria. ISBN 3-900051-07-0, URL http://www.R-project.org.

Romero R, Guijarro J, Alonso S. 1998. A 30 year (1964-1993) daily rainfall data base for the Spanish Mediterranean regions: first exploratory study. International Journal of Climatology 18: 541- 560, DOI: 10.1002/(SICI)1097-0088(199804)18:5<541::AID-JOC270>3.0.CO;2-N

Roncoli C, Ingram K, Kirshen P. 2001. The costs and risks of coping with drought: livelihood impacts and farmers' responses in Burkina Faso. Clim Res 10: 119-132

Rouche N, Ardoin-Bardin S, Boyer JF, Brissaud B, Cres A, Dieulin C, Mahe G. 2008. Constitution d'une grille de pluies mensuelles periode 1900-2000 pour l'Afrique. CD-ROM, actes du $13^{\mathrm{eme}}$ congres mondial de l'eau : Montpellier, France, septembre 2008.

Smakhtin VU, Hughes DA. 2007. Automated estimation and analyses of meteorological drought characteristics from monthly rainfall data. Environmental Modelling and Software 22: 880-890, DOI: $\underline{10.1016 / \text { j.envsoft.2006.05.013 }}$

Sönmez FK., Kömüscü AÜ, Erkan A, Turgu E. 2005. An analysis of spatial and temporal dimension of drought vulnerability in Turkey using the Standardized precipitation Index. Natural Hazards 35: 243-264, DOI: $10.1007 / \mathrm{s} 11069-004-5704-7$

Soumaguel A. 1996. Elaboration des fichiers Opérationnels pour le calcul Régionalisé des pluies par la méthode du vecteur Régional (MVR) sur le bassin versant du Niger. Rapport d'activité FRIEND-AOC, Bamako, ORSTOM, Laboratoire d'hydrologie, 35 p. 
Sullivan C, Meigh J. 2005. Targeting attention on local vulnerabilities using an integrated index approach: the example of the Climate Vulnerability Index. Water Science and Technology 51: 69-78

Traore SB, Reyniers FN, Vaksmann M, Kone B, Sidibe A, Yorot A, Yattara K, Kouressy M. 2000. Adaptation a la secheresse des ecotypes locaux de sorghos au Mali. Secheresse 11 (4): 227-237.

Vörösmarty CJ, Douglas EM, Green PA, Revenga C. 2005. Geospatial indicators of emerging water stress: an application to Africa. Ambio 34 (3): 230-237.

Wu H, Hayes MJ, Weiss A, Hu Q. 2001. An evaluation of the Standardized Precipitation Index, the China Z-index and the statistical Z-score. International Journal of Climatology 21: 745-758. DOI: 10.1002/joc. 658

\section{Index of tables}

\begin{tabular}{llc}
\hline SPI value & Category & Probability \% \\
\hline 2.00 or more & Extremely wet & 2.3 \\
1.5 to 1.99 & Severely wet & 4.4 \\
1.00 to 1.49 & Moderately wet & 9.2 \\
0 to 0.99 & Mildly wet & 34.1 \\
0 to -0.99 & Mild drought & 34.1 \\
-1.00 to -1.49 & Moderate drought & 9.2 \\
-1.50 to -1.99 & Severe drought & 4.4 \\
-2 or less & Extreme drought & 2.3
\end{tabular}

Table 1: classification of events, according to the SPI (Lloyd-Hughes and Saunders, 2002) 


\begin{tabular}{lccc}
\hline & $\begin{array}{c}\text { Degraded SPI- } \\
\text { 10d }\end{array}$ & Original SPI-10d & Relative difference \\
& 13.8 & 8.2 & 65 \\
\hline Mean drought & & \\
duration (days) & & & \\
Maximum & 55.0 & 48.0 & 14.6 \\
drought duration & & & \\
(days) & & & \\
Mean number of & 3.2 & 5.5 & -42.6 \\
drought & & & \\
Précipitation & 6.69 & 6.83 & \\
threshold (mm) & & & \\
\hline
\end{tabular}

Table 2 : comparison between 'original' and 'degraded' SPI using 4 parameters. 'Degraded' is referring to the attempt described. Relative difference is ((Degraded-Original)/Original)*100

\begin{tabular}{ll}
\hline \multicolumn{1}{c}{ EDI } & \multicolumn{1}{c}{ Description } \\
\hline-0.69 to 0 & Mild drought \\
-0.7 to -1.49 & Moderate drought \\
-1.5 to -2.49 & Severe drought \\
$<-2.5$ & Extreme drought \\
\hline
\end{tabular}

Table 3 : classification of droughts according to the EDI 


\begin{tabular}{lcc}
\hline \multicolumn{1}{c}{ Classification } & Average (\%) & Sdv (\% of average) \\
\hline Good & 58.5 & 7.6 \\
Intermediate & 31.8 & 3.6 \\
Bad & 9.7 & 4.6 \\
\hline
\end{tabular}

Table 4 : comparison of each 5 days group classification (SPI vs EDI). "Average" is the average of each station's percentage of days classified as "good" or "bad". Here is used a degraded version of EDI.

Standardized (each drought category has a given Created for daily data

return period) and well known Good use of daily data

$+$

Relatively easy to compute No station rejected

Free access routines already exist

Very hard to compute at a daily time step Difficult to understand quickly

Limitation due to Gamma distribution (stations Time of calculation

- $\quad$ rejected) Few studies on it

Loss of information No free access routines 


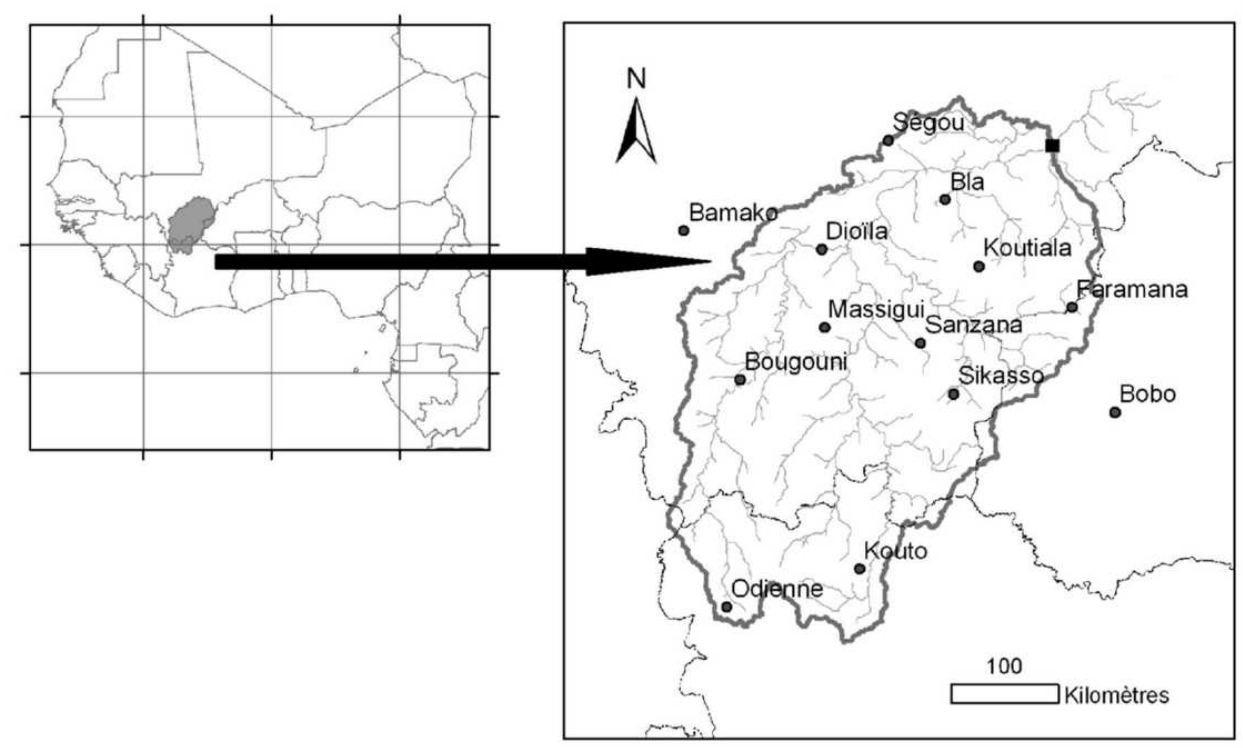

Figure 1: General situation of Bani watershed. The outlet (square) is in this study located at Beneny Kegny. 




Figure 2: The 51 selected stations. They are clustered in 5 groups following the global shape of annual isohyets (average on years 1963/2000). 



Figure 3: Percentage of daily data available per station from 1963 to 2000. 


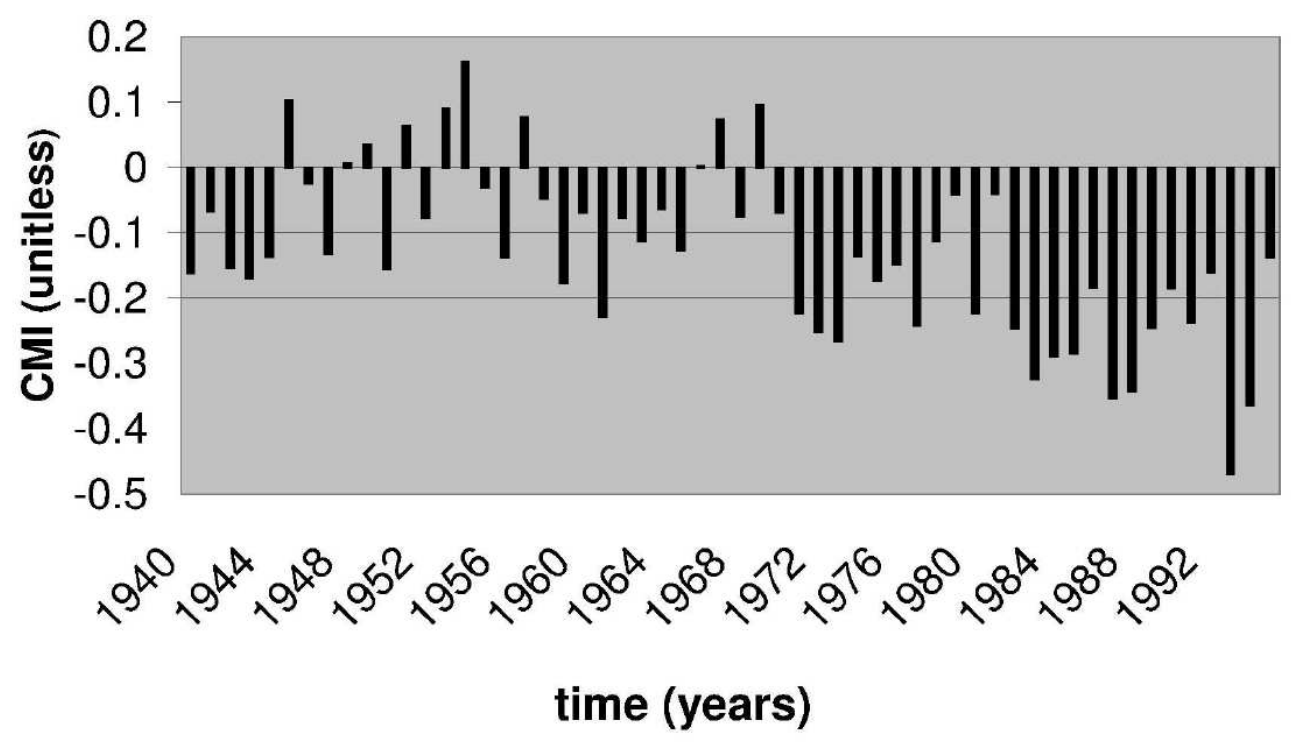

Figure 4: Evolution of CMI from 1940 to 1995 on a southern mesh of the basin. 



Figure 5: Average CMI computed for (a) years 1940/1970 and (b) 1971/1995. Figures (c) and (d) show the Coefficient of Variablity ( $\mathrm{CV}=\mathrm{sdv} / \mathrm{average})$ of each period. 


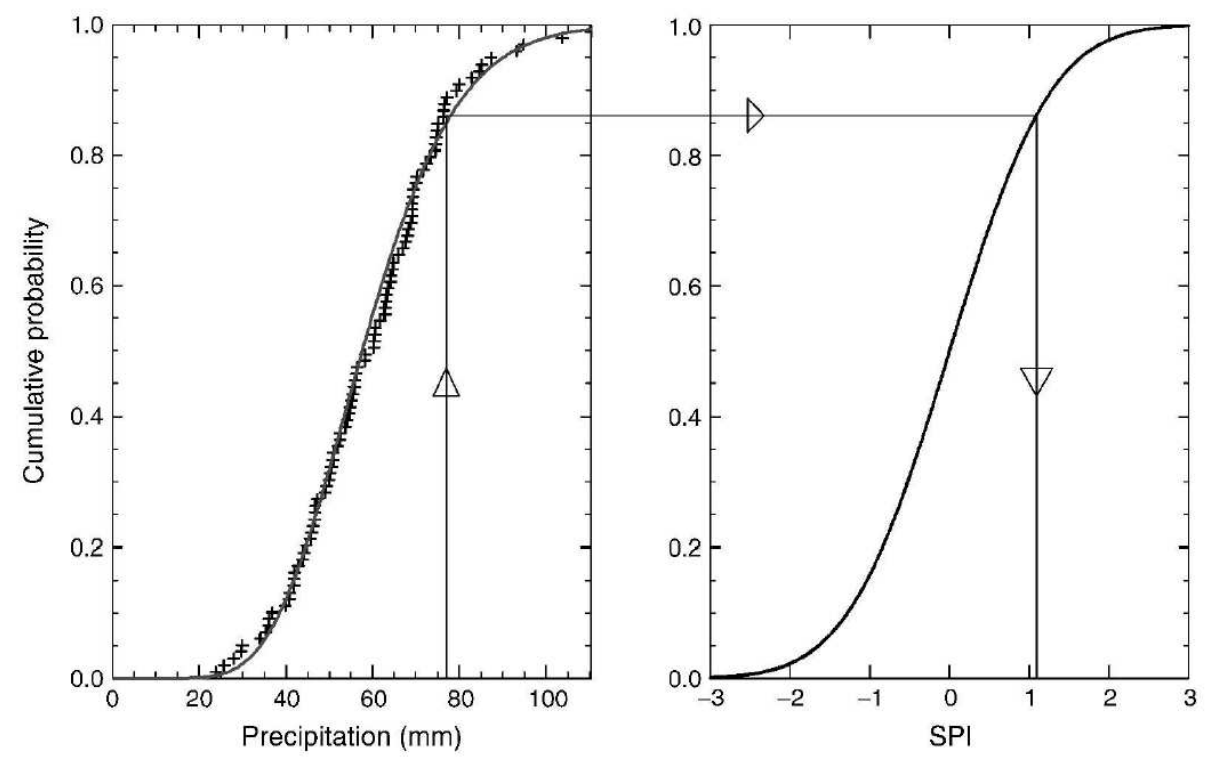

Figure 6: Example of an equiprobability transformation from a fitted gamma distribution to the standard normal distribution. Data are for the 3 month (DJF) average precipitation over the southeast of England (Lloyd-Hughes and Saunders, 2002) 

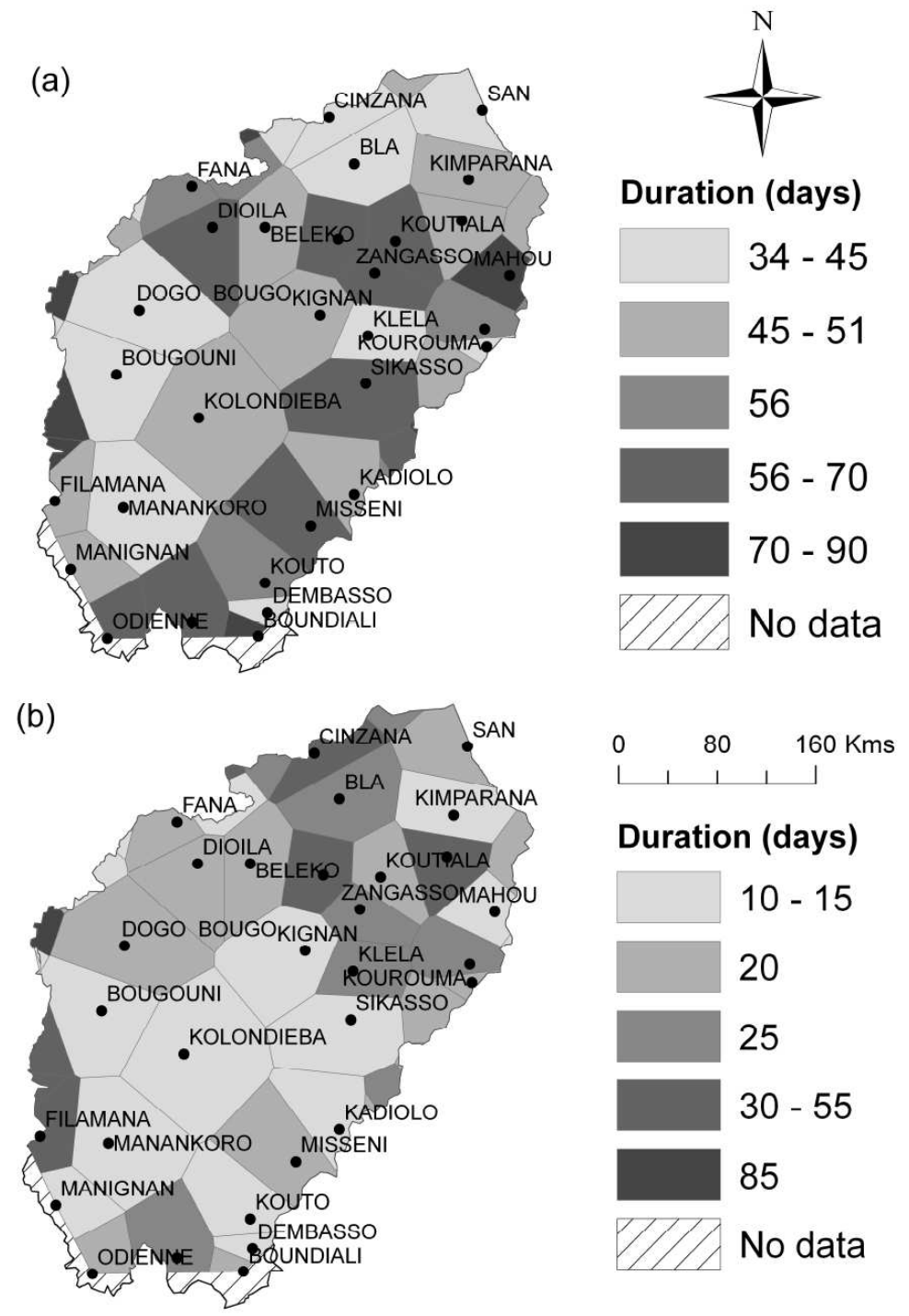

\section{Duration (days)}



Figure 7: Maximum drought duration for all kinds of droughts (i.e SPI-10d<0) (a) and for extreme+severe droughts (i.e SPI-10d<-1.5) (b). Duration is the number of days with consecutive SPI negative values. Period studied is from 1963 to 2000 , considering only July to September. 

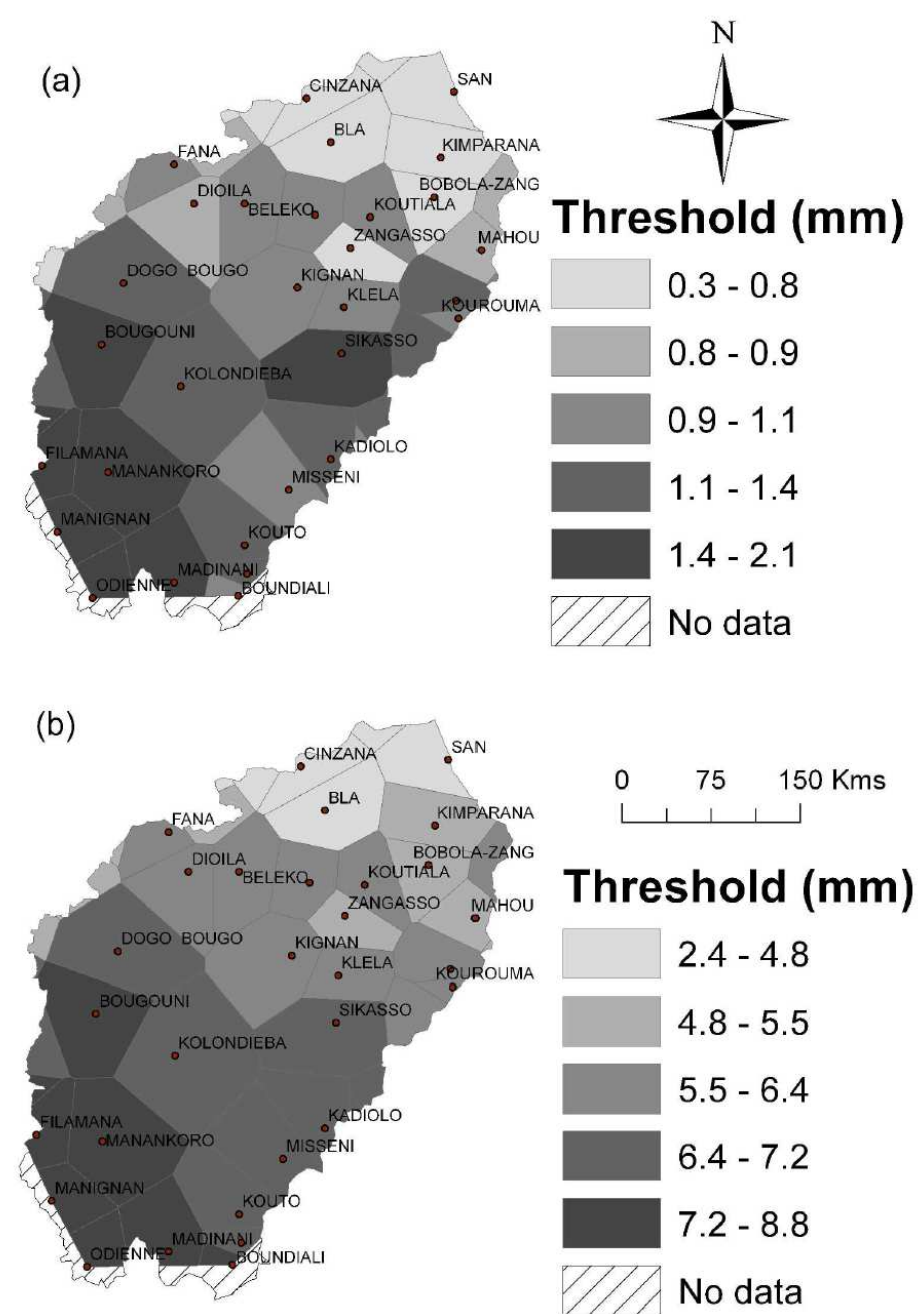

Figure 8: Precipitation thresholds of the category (a) mild droughts (SPI-10d $<0$ ) and (b) extreme droughts (SPI-10d<-2), computed thanks to the SPI-10d from 1963 to 2000 (July to September). 



(b)

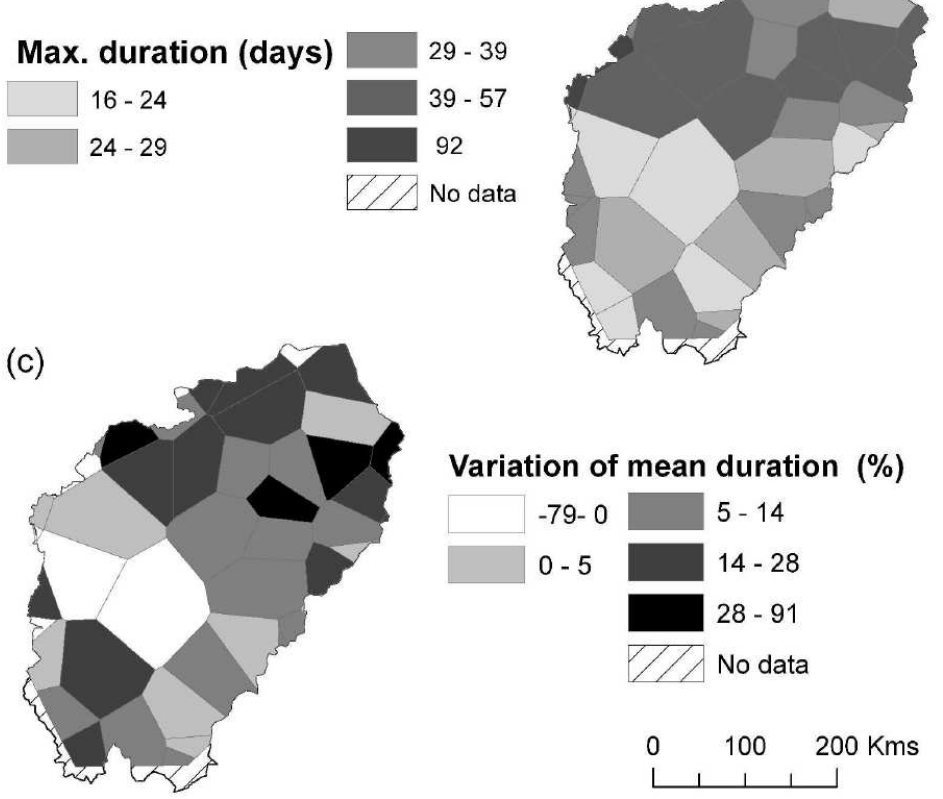

Figure 9: Study of droughts duration with the EDI, i.e consecutive days with negative EDI value This is for all kind of droughts $(E D I<0)$ and shows for years $1963 / 2000$ (July to September) annual mean drought duration (a), maximum drought duration (b) and variation of mean drought duration (c) i.e : ((Duration 1971/2000 - Duration 1963/1970)/Duration 1963/1970)*100. White regions represent a diminution of droughts duration. 




\section{Mean duration (days)}



(b)
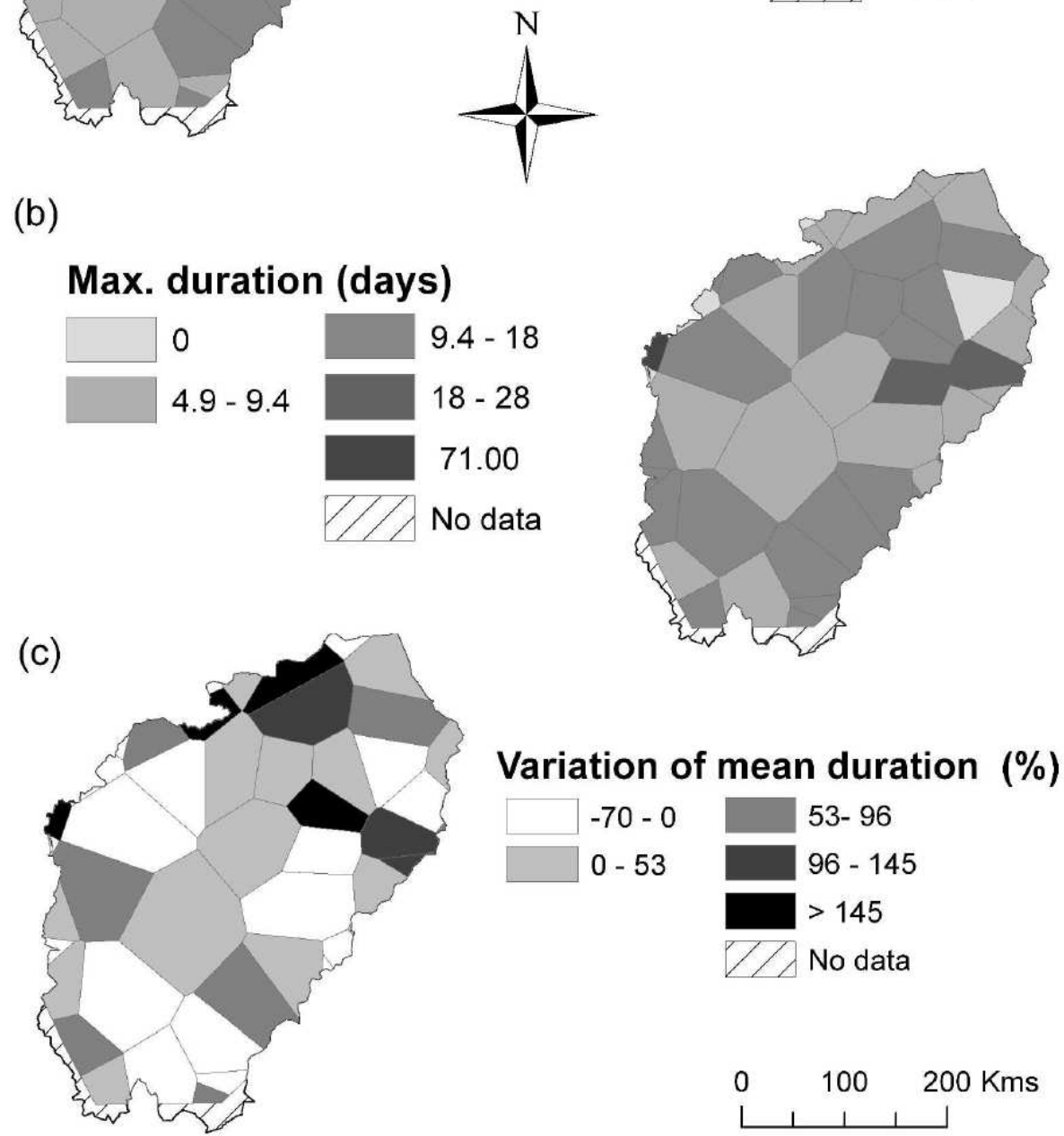

Variation of mean duration (\%)

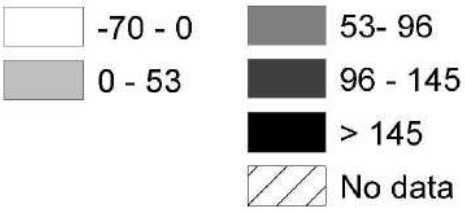

Figure 10: Same as Figure 9 but with extreme+severe droughts $(E D I<-1.5)$ $210 \times 296 \mathrm{~mm}(600 \times 600$ DPI $)$ 

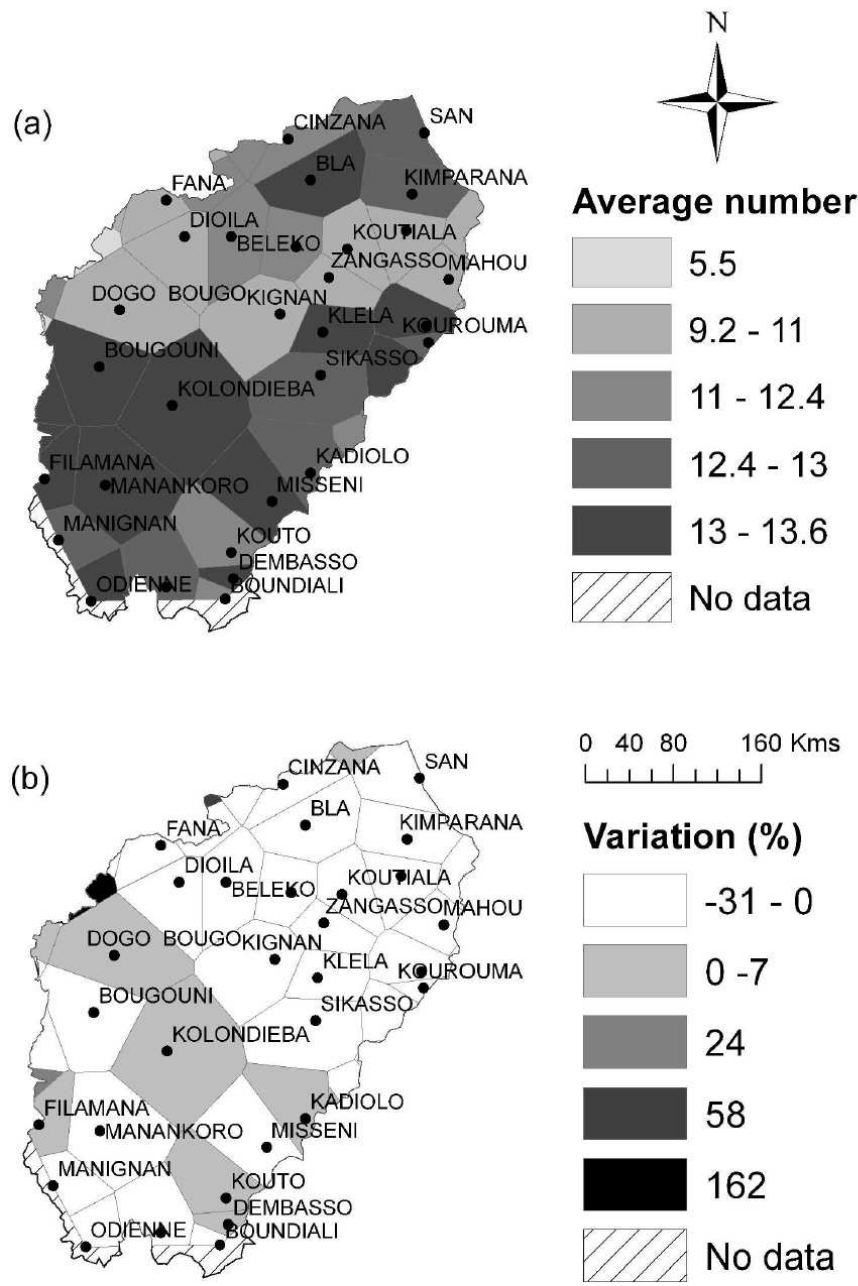

$04080 \quad 160 \mathrm{Kms}$

Variation (\%)

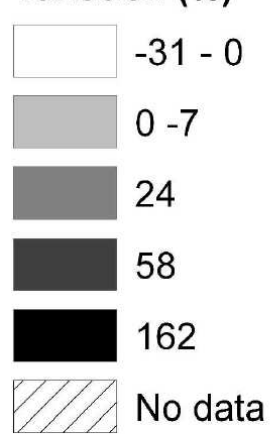

Figure 11: Average number of droughts (a) I.e average number of groups constituted of consecutive days with negative EDI value. This is for all kind of droughts (EDI<0) and shows for years $1963 / 2000$ (July to September). The variation of the number of droughts is also presented (b), with the same definition of variation as in Figure 9. 
(a)


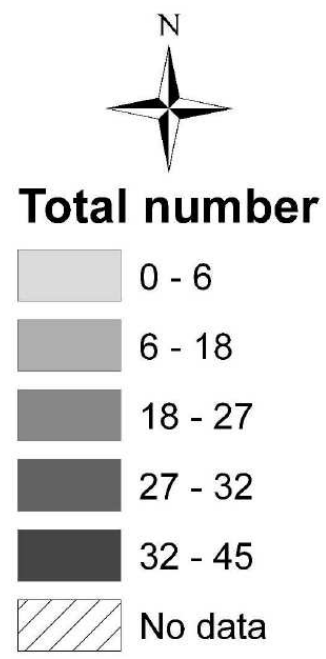

$0 \quad 4080 \quad 160 \mathrm{Kms}$

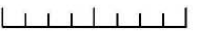

Variation (\%)

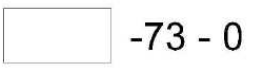

$0-49$

$49-120$

$120-190$

$>200$

No data

Figure 12: Same as Figure 11 but with extreme+severe droughts $(E D I<-1.5)$. Here is drawn total number of droughts 
(a)

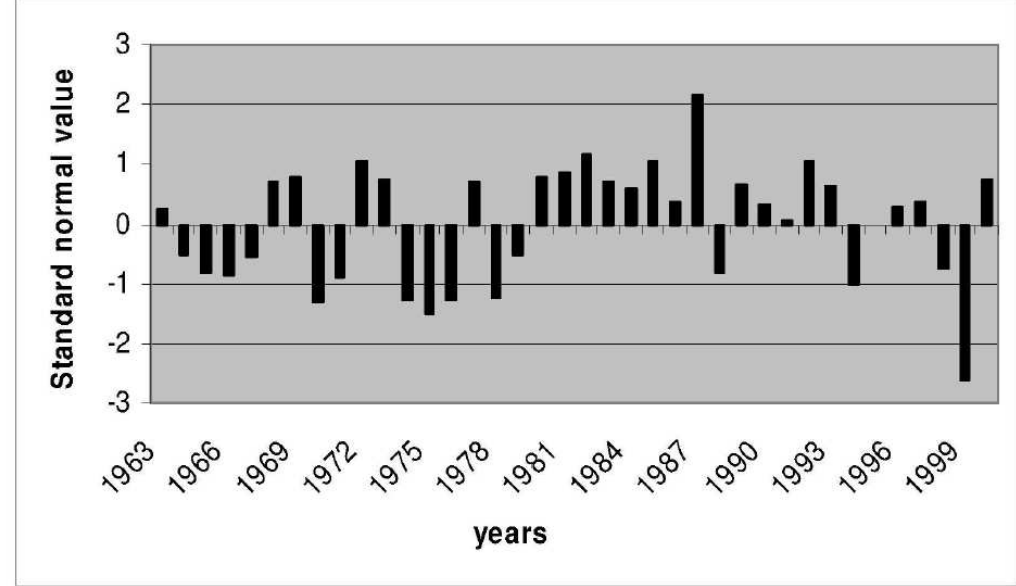

(b)

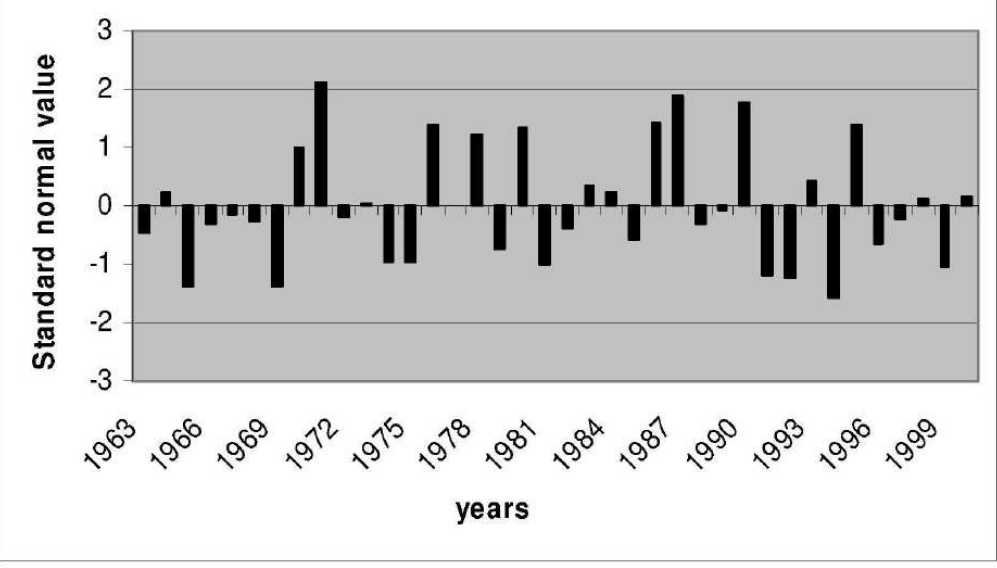

Figure 13: Evolution of total number of days classified in drought $(E D I<0,(a))$ and extreme+severe drought (EDI<-1.5 (b)), sum on the whole basin. $Y$ axis represents standard normal value, $X$ axis represents years 1963 to 2000 . 

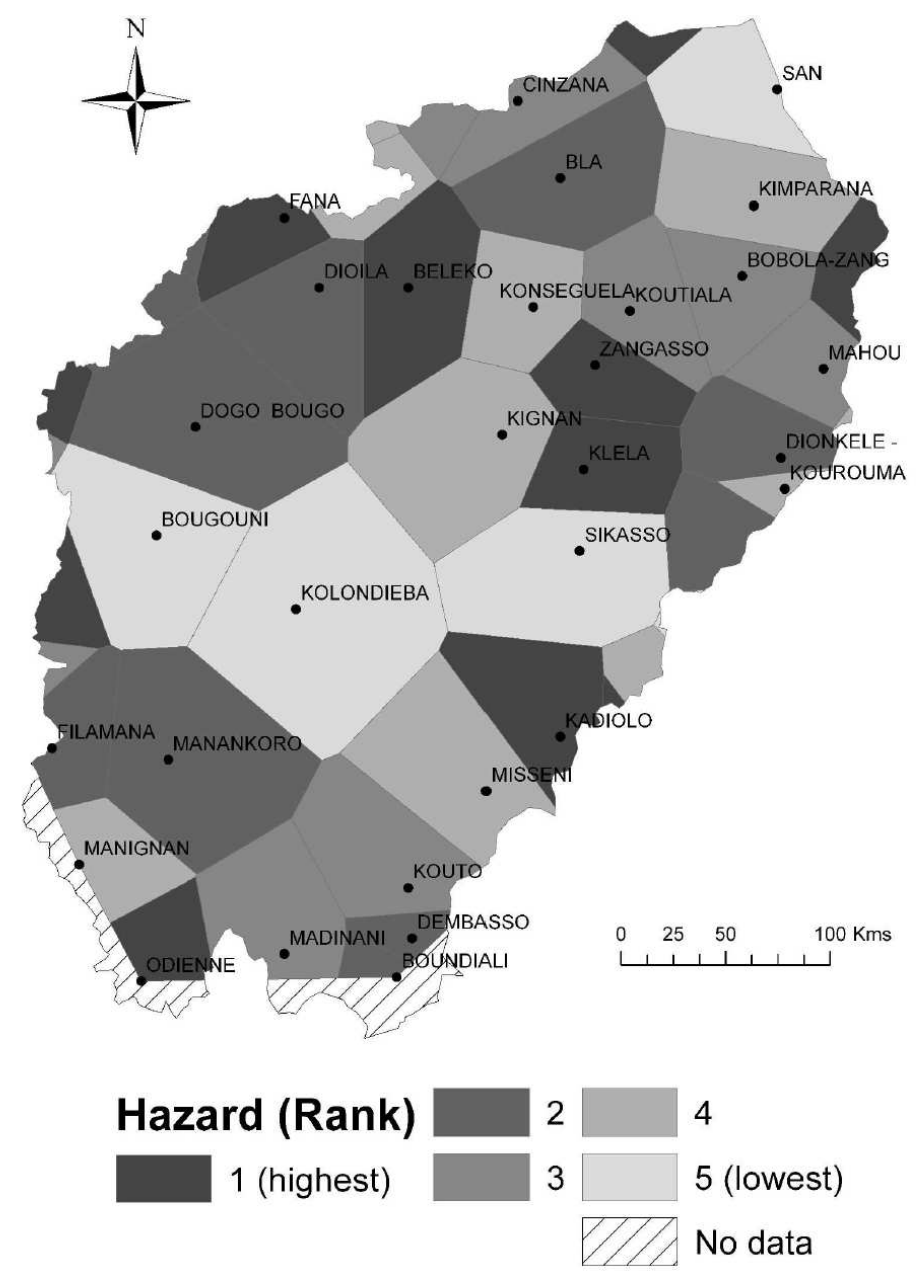

Figure 14: General assessment of drought hazard on the Bani watershed using EDI with daily data, from 1963 to 2000 (July to September). the description of the calculation is in section 5.2. 


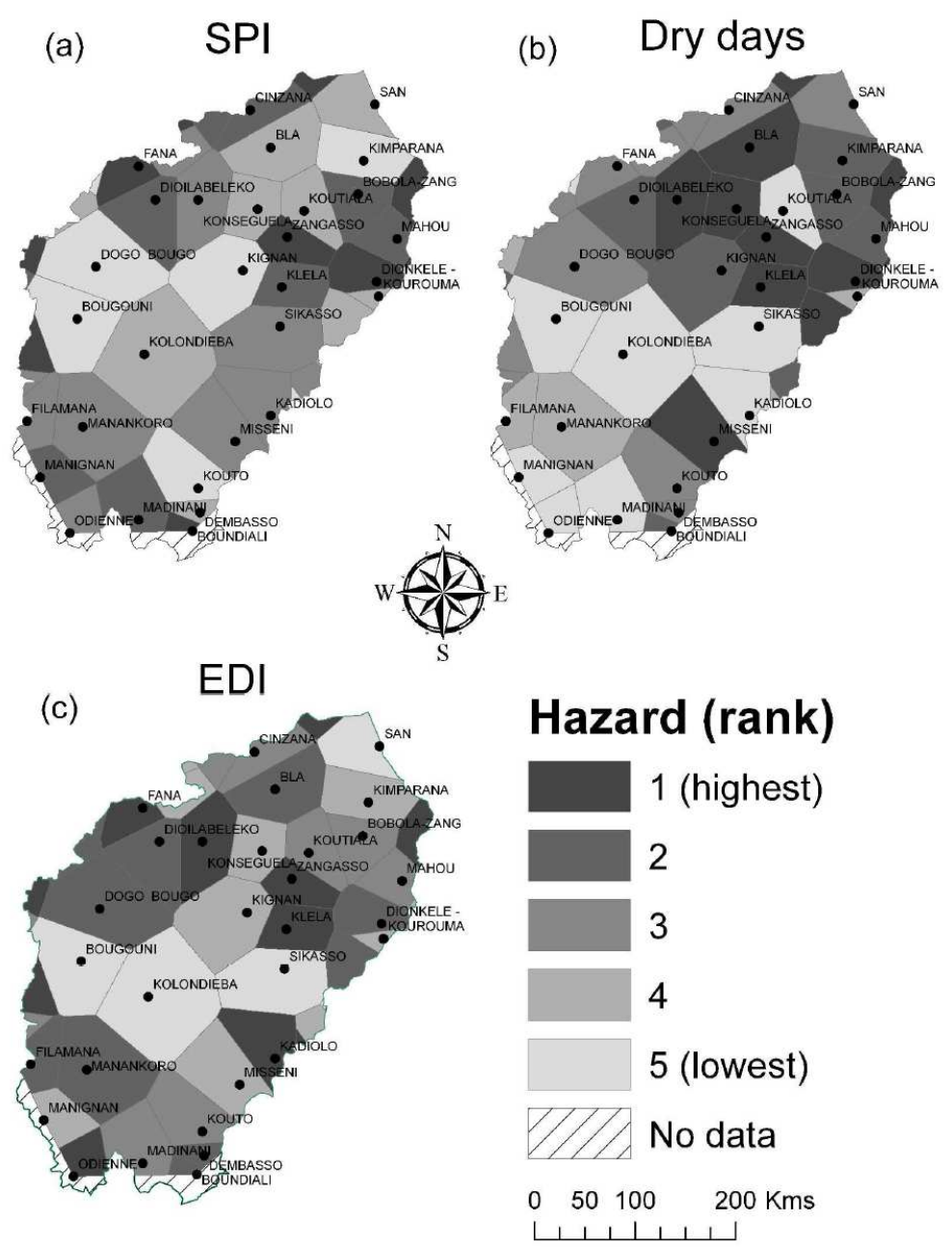

Figure 15: Comparison of 3 assessments of droughts hazard using SPI(a), Dry days (b) and EDI (c). Dry days are days without rainfall. 